\title{
TRATAMENTO DE SOLO ARENOSO CONTAMINADO COM DIESEL UTILIZANDO MÉTODO INOVADOR DE ATIVAÇÃO PARA O PERÓXIDO DE HIDROGÊNIO
}

\author{
A. R. de SOUZA ${ }^{1}$, A. G. da CÂMARA ${ }^{1}$, S. S. O. da SILVA ${ }^{1}$, C. K. O. SILVA²; M. M. G. R. \\ VIANNA ${ }^{2}$, O. CHIAVONE-FILHO ${ }^{1}$, C. A. O. NASCIMENTO ${ }^{2}$ \\ ${ }^{1}$ Universidade Federal do Rio Grande do Norte, Departamento de Engenharia Química \\ ${ }^{2}$ Universidade de São Paulo, Departamento de Engenharia Química \\ E-mail para contato: ramos.alessandra@hotmail.com
}

\begin{abstract}
RESUMO - A contaminação de solos e aquíferos freáticos por hidrocarbonetos é um dos mais frequentes exemplos de passivos ambientais causados por armazenamento de resíduos sólidos, disposição ou lançamentos de efluentes inadequados, representando um risco para as fontes de abastecimento e para a saúde humana. Com o agravamento desse problema devido ao aumento no consumo de derivados do petróleo, é crescente o número de pesquisas que visam potencializar a remoção destes poluentes, remediando este tipo de situação e restaurando a qualidade da água e do solo. Neste estudo foi testado um método inovador para a ativação do peróxido de hidrogênio na remediação de solos contaminados com óleo diesel. Consiste no uso de catalisador heterogêneo constituído por diatomita (suporte) e íons de $\mathrm{Fe}^{2+}$ e $\mathrm{Fe}^{3+}$. Foram realizados experimentos em batelada a fim de verificar a eficiência do catalisador sintetizado e da solução de $\mathrm{Fe}^{2+}$ para ativação do peróxido de hidrogênio na degradação em solo arenoso contaminado com diesel dissolvido em hexano, e também para analisar as melhores concentrações de catalisador e peróxido de hidrogênio a serem utilizadas, com monitoramento do teor de carbono total presente antes e após a degradação do contaminante. Com o estudo foi constatado que a ativação do peróxido de hidrogênio pelo catalisador sintetizado foi mais eficiente do que a ativação via solução de $\mathrm{Fe}^{2+}$, e que a variação na concentração de peróxido é mais significante que a variação do catalisador na degradação.
\end{abstract}

\section{INTRODUÇÃO}

A indústria petrolífera é apenas um dentre os principais responsáveis pelos impactos negativos causados ao meio ambiente. Alterações na qualidade do solo e das águas subterrâneas são decorrentes da contaminação devido a vazamentos, que podem ocorrer desde a fase de exploração até o processamento e armazenamento do petróleo e seus derivados (Mariano, 2001).

Os acidentes causados por vazamentos de hidrocarbonetos ocorrem, quase sempre, em áreas urbanas, densamente povoadas, podendo resultar em incêndios e explosões em espaços confinados, destacando-se: os sistemas subterrâneos de águas pluviais, esgoto, telefonia, 


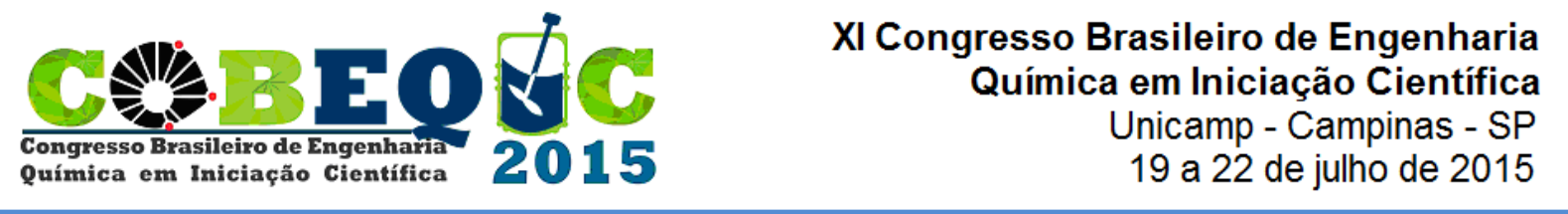

metrô, eletrificação, subsolo de edificações, garagens subterrâneas, escavações, poços de água, entre outros (Favera, 2008).

\subsection{Contaminação do Solo}

O óleo diesel é um combustível derivado do petróleo, produzido a partir do refino deste através do processo de craqueamento ou destilação fracionada do óleo cru, onde são obtidas as frações de óleo diesel leve e pesado, básicas para a produção de óleo diesel. Em paralelo com a crescente produção e comercialização deste derivado, surgiu a preocupação com a contaminação do solo e das águas subterrâneas que ocorre devido a vazamentos em tanques subterrâneos de estocagem em postos de combustíveis (Mariano, 2006). Na cidade de Natal, capital do Estado do Rio Grande do Norte, entre os empreendimentos potencialmente ou parcialmente poluidores que comprometem a qualidade da água da cidade, tem-se os postos revendedores de combustíveis, uma vez que apenas 110 postos de combustíveis da cidade se encontravam de acordo com a Resolução CONAMA 273, até o ano de 2009 (Aquino Sobrinho, 2011).

\subsection{Técnicas de Remediação}

A remediação do solo contaminado pode ser feita, principalmente, de duas maneiras: tratamento in situ e tratamento ex situ. No tratamento in situ a remediação é realizada no local da contaminação, sem a necessidade de remoção do solo. No entanto, no tratamento ex situ há a necessidade da remoção do solo, o qual será remediado em outro local. Os tratamentos in situ são frequentemente mais utilizados por apresentarem melhor custo-benefício do que a remediação ex situ (Palmroth et al, 2006). Dentre as técnicas de tratamento in situ tem-se a oxidação química in situ (ISCO), técnica viável para a remediação de locais contaminados com poluentes orgânicos. Existem diferentes oxidantes que são utilizados na oxidação química in situ. A eficácia da decomposição de peróxido de hidrogênio catalisada para oxidação química in situ (ISCO) do solo e da água subterrânea contaminada é bem estabilizada, onde o peróxido de hidrogênio é ativado por ferro (II), gerando um radical hidroxila $(\bullet \mathrm{OH})$, responsável pela degradação dos poluentes, conforme a Equação 1:

$$
\mathrm{Fe}^{2+}+\mathrm{H}_{2} \mathrm{O}_{2} \rightarrow \mathrm{Fe}^{3+}+\mathrm{HO} \bullet+\mathrm{OH}^{-}
$$

Os objetivos foram preparar um material heterogêneo, com a diatomita como suporte, sobre o qual é precipitada uma mistura de íon ferroso $\left(\mathrm{Fe}^{2+}\right)$ e íon férrico $\left(\mathrm{Fe}^{3+}\right)$ para ativar o peróxido de hidrogênio e estudar a viabilidade desse sistema para degradação do diesel.

\section{METODOLOGIA}

\subsection{Síntese e Caracterização do Material}

A modificação da diatomita foi realizada utilizando-se $100 \mathrm{~g}$ de diatomita bruta, na qual foi adicionada lentamente a $112 \mathrm{~mL}$ de uma solução aquosa contendo $\mathrm{Fe}_{2}\left(\mathrm{SO}_{4}\right)_{3}\left(366\right.$ g.L $\left.\mathrm{L}^{-1}\right)$ e $\mathrm{FeSO}_{4} \cdot 7 \mathrm{H}_{2} \mathrm{O}\left(183\right.$ g.L $\left.\mathrm{L}^{-1}\right)$, em um reator de mistura intensa. Nessa suspensão foram adicionadas, em 4 etapas, $220 \mathrm{~mL}$ de uma solução de $\mathrm{NaOH}$ a 5 mol.L-1. A mistura permaneceu em homogeneização por 1 hora. O material sintetizado, CAT-5, foi lavado por filtração a vácuo, para remoção dos possíveis subprodutos indesejáveis formados durante a 
síntese e do excesso de $\mathrm{NaOH}$. Após a lavagem, o material foi mantido em estufa a $60^{\circ} \mathrm{C}$ por 24 horas. Após a secagem, o catalisador foi moído (desagregado) com almofariz e pistilo, e depois peneirado e condicionado em frascos de vidro.

Para caracterizar o material foram realizadas análises de difração e fluorescência de raio-x nas amostras de diatomita bruta e diatomita modificada.

\subsection{Experimentos em Batelada}

As amostras de diesel comercial e solo foram as mesmas utilizadas no estudo de Fernandes e Chiavone-Filho (2014). O diesel comercial foi adquirido em um posto de gasolina da cidade de Natal-RN. O solo, de característica arenosa, apresenta baixo teor de matéria orgânica $(0,13 \%$ de teor de carbono orgânico total) e foi coletado em Natal-RN a uma profundidade de $30 \mathrm{~cm}$ com auxílio de trado manual, quarteada e passada em peneira de 2 $\mathrm{mm}$. O material passante foi destorroado e aquecido em estufa a $55^{\circ} \mathrm{C}$, por 24 horas.

Para todos os ensaios, em erlenmeyers de $125 \mathrm{~mL}$ foram pesados $15 \mathrm{~g}$ de solo arenoso contaminado em laboratório com diesel dissolvido em hexano, obtendo concentração final de 5000 ppm de contaminante. Para o tratamento foram adicionados os volumes das soluções do oxidante e completado com água destilada até o volume de $30 \mathrm{~mL}$. A quantidade de catalisador foi adicionada e o sistema foi homogeneizado, sendo a reação realizada a temperatura ambiente de $28^{\circ} \mathrm{C}$.

Em ensaios de 4 horas de reação, foram comparadas as eficiências do CAT-5 (diatomita modificada) e da solução de $\mathrm{Fe}^{2+}$ solúvel na ativação do peróxido de hidrogênio na degradação do diesel comercial em solo contaminado. A concentração de $\mathrm{Fe}^{2+}$ foi em quantidade aproximada de ferro total presente no CAT-5. As condições foram: peróxido de hidrogênio $\left(100 \mathrm{mmol} \mathrm{L}^{-1}\right), \mathrm{FeSO}_{4} .7 \mathrm{H}_{2} \mathrm{O}\left(33 \mathrm{~g} \mathrm{~L}^{-1}, \mathrm{Fe}^{+2}=0,19 \mathrm{~g}\right)$ e CAT-5 $(1 \mathrm{~g}$, equivalente a $0,17 \mathrm{~g}$ de $\mathrm{Fe})$.

Para estudar as melhores condições das variáveis (concentração de peróxido de hidrogênio e quantidade de CAT-5), foi realizado um planejamento experimental fatorial $2^{2}$, com solo arenoso contaminado com diesel em 24 horas de reação. As condições empregadas neste planejamento estão apresentadas na Tabela 1. Para análise do planejamento experimental foi utilizado o Software Statistica 12.

Tabela 1 - Planejamento experimental fatorial para a degradação do diesel

\begin{tabular}{ccccc}
\hline Ensaio & \multicolumn{2}{c}{ Valores Nornalizados } & \multicolumn{2}{c}{ Valores absolutos } \\
\cline { 2 - 5 } & CAT-5 & $\begin{array}{c}\text { Peróxido } \\
\text { de Hidrogênio }\end{array}$ & $\begin{array}{c}\text { CAT-5 } \\
(\mathrm{g})\end{array}$ & $\begin{array}{c}\text { Peróxido } \\
\text { de Hidrogênio } \\
\left(\mathrm{mmol} \mathrm{L}^{-1}\right)\end{array}$ \\
\hline 1 & 1 & 1 & 1 & 100 \\
2 & -1 & -1 & 0,5 & 50
\end{tabular}




$\begin{array}{ccccc}3 & -1 & +1 & 0,5 & 100 \\ 4 & +1 & -1 & 1 & 50 \\ 5 & 0 & 0 & 0,75 & 75\end{array}$

Análise: Amostras de cada ensaio foram analisadas para a determinação de carbono total residual, utilizando o equipamento TOC - VCPH acoplado ao módulo de sólidos SSM5000A da Shimadzu.

\section{RESULTADOS}

\subsection{Caracterização}

De acordo com a análise de fluorescência de raio-x, os teores de íons de ferro total foram 4,78\% e 17,65\%, para as amostras de diatomita bruta e diatomita modificada, respectivamente. Esses resultados indicam um aumento significativo na quantidade de íons de ferro após a síntese.

Nos resultados da análise de difração de raio-x, não foi possível detectar a presença dos óxidos ou hidróxidos de ferro formados, pois o material formou cristais em quantidades muito baixas para serem detectados, implicando em característica amorfa das diatomitas bruta e modificada.

\subsection{Tratamento de Solo Arenoso Contaminado com Diesel em Batelada}

A Figura 1 apresenta os resultados da degradação do diesel utilizando peróxido de hidrogênio ativado por CAT-5 e ativado via $\mathrm{Fe}^{2+}$, em 4 horas de reação. O CAT-5 apresentou melhor eficiência degradando $45 \%$ de diesel, enquanto que a ativação via $\mathrm{Fe}^{2+}$ degradou aproximadamente $20 \%$. A partir desses resultados, pode-se concluir que o CAT-5 apresenta melhor eficiência para ativar os oxidantes persulfato de sódio e peróxido de hidrogênio para a degradação do diesel, do que via $\mathrm{Fe}^{2+}$, nas condições equivalentes de ferro.

Figura 1 - Decaimento do teor de carbono total do diesel no sistema peróxido de hidrogênio em 4 horas de reação.

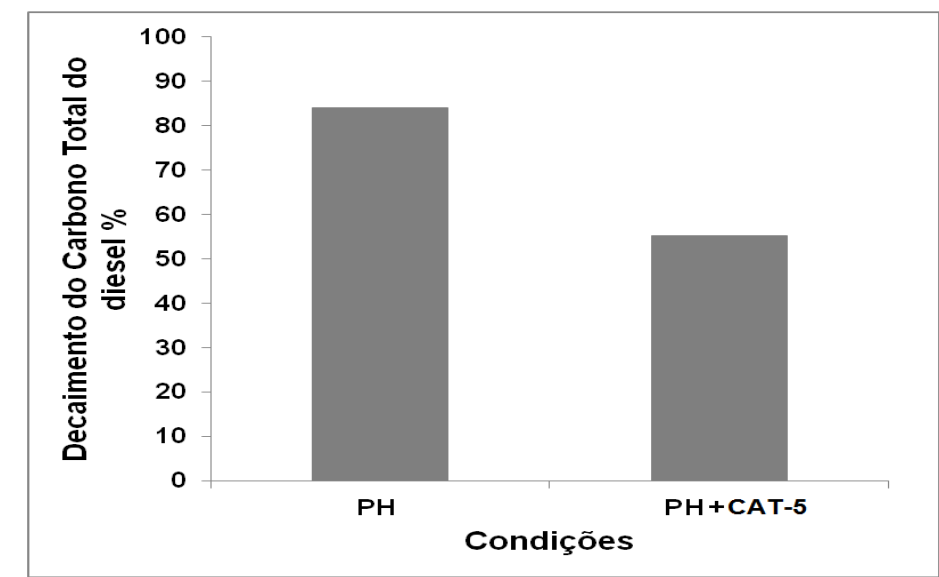


A Tabela 2 e a Figura 2 apresentam os resultados do planejamento experimental $2^{2}$ realizado em 24 horas com peróxido de hidrogênio. A máxima degradação de diesel foi aproximadamente $60 \%$, utilizando $1 \mathrm{~g}$ de CAT-5 com $100 \mathrm{mmol}^{-1} \mathrm{~L}^{-1}$ de peróxido de hidrogênio. Esse resultado mostra que deve-se adicionar o peróxido de hidrogênio aos poucos, dado que o radical hidroxila tem tempo de meia vida curto. Esse pode ser um dos motivos da pouca diferença de degradação do diesel observada em 4 horas atingindo $45 \%$, conforme a Figura 1, e em 24 horas com 58\%, conforme a Tabela 2, em que peróxido de hidrogênio foi adicionado apenas no início da reação.

Os ensaios utilizando peróxido de hidrogênio a $100 \mathrm{mmol} \mathrm{L}^{-1}$ no menor nível de CAT-5 $(0,5 \mathrm{~g})$ e no maior nível de CAT-5 $(1,0)$ também apresentou diferença de degradação pouco significativa, e isso pode ser inferido que a menor quantidade de CAT-5 pode ser utilizada.

Tabela 2 - Resultados do planejamento experimental fatorial para degradação de diesel

\begin{tabular}{cccc}
\hline \multirow{2}{*}{ Ensaio } & \multicolumn{2}{c}{ Valores absolutos } & Resposta \\
\cline { 2 - 4 } & $\begin{array}{c}\text { Diatomita } \\
\text { modificada } \\
(\mathrm{g})\end{array}$ & $\begin{array}{c}\text { Peróxido de } \\
\text { Hidrogênio } \\
\left(\text { mmol L }^{-1}\right)\end{array}$ & $\begin{array}{c}\text { Degradação do } \\
\text { teor do carbono } \\
\text { total presente no } \\
\text { diesel }\end{array}$ \\
\hline 1 & 1 & 100 & 58 \\
2 & 0,5 & 50 & 36 \\
3 & 0,5 & 100 & 54 \\
4 & 1 & 50 & 40 \\
5 & 0,75 & 75 & 55 \\
\hline
\end{tabular}

Figura 2 - Superfície de resposta do planejamento fatorial $2^{2}$ para degradação de diesel (5000 $\left.\mathrm{mg} \mathrm{kg}^{-1}\right)$. Concentração do peróxido de hidrogênio variando de $50 \mathrm{mmol} \mathrm{L}-1-100 \mathrm{mmol} \mathrm{L}^{-1} \mathrm{e}$ quantidade de CAT-5 variando de 0,5 - 1,0 g.

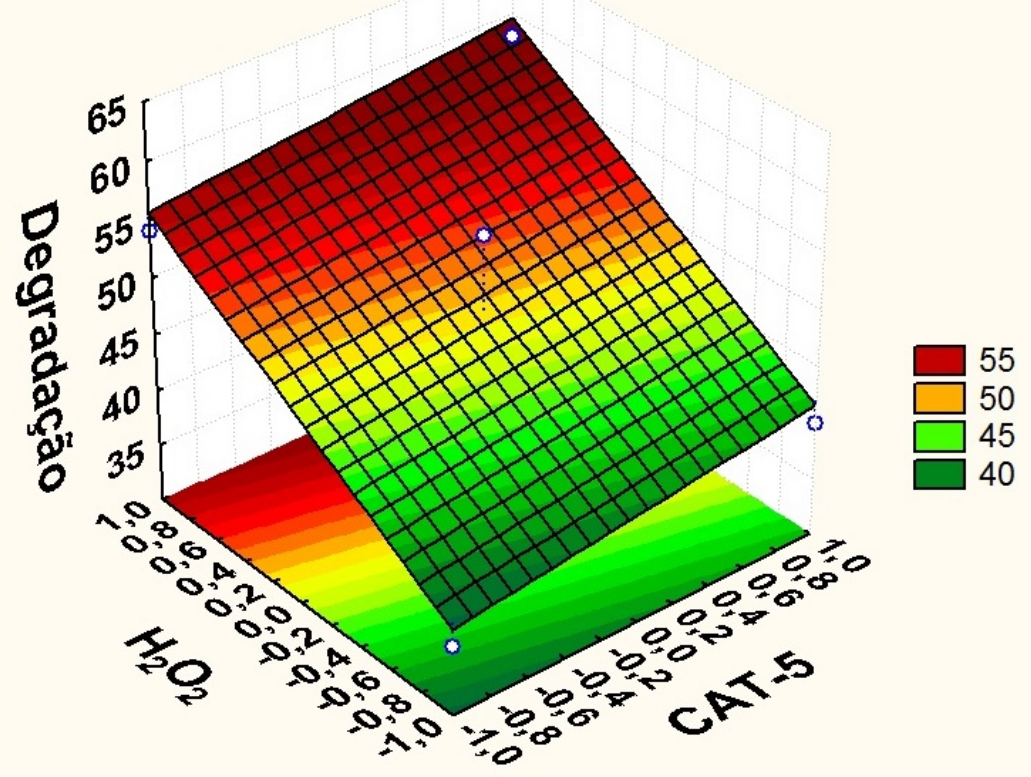


No cálculo do efeito das variáveis do planejamento experimental para a degradação do diesel, verifica-se que os efeitos do catalisador e do oxidante apresentaram valores positivos. O efeito da variável concentração de peróxido de hidrogênio apresentou valor igual a 18, o que indica que a eficiência da degradação aumenta $18 \%$, em média, quando a concentração do peróxido de hidrogênio varia do nível mais baixo $\left(50 \mathrm{mmol} \mathrm{L}^{-1}\right)$ para o nível mais alto $(100$ mmol L-1). O CAT-5 apresentou valor igual a 4, indicando que a degradação aumenta $4 \%$, em média, quando a quantidade de CAT-5 varia de nível mais baixo $(0,5 \mathrm{~g})$ para o nível mais elevado $(1 \mathrm{~g})$. Por esses resultados, infere-se que a variável concentração do peróxido de hidrogênio apresenta maior significância do que quantidade de CAT-5. reais.

Este estudo apresentou a viabilidade do material proposto nesta pesquisa em amostras

\section{CONCLUSÕES}

A avaliação da eficiência do CAT-5 para o tratamento de solo arenoso contaminado com diesel indicou significativa atividade catalítica utilizando peróxido de hidrogênio como oxidante na produção do radical hidroxila. Os resultados desses ensaios sugerem que o peróxido de hidrogênio seja adicionado, gradativamente, ao longo da reação, uma vez que o radical hidroxila tem tempo de meia-vida muito curto.

\section{REFERÊNCIAS}

AQUINO SOBRINHO. H.L. Design gráfico da pluma de contaminação por compostos orgânicos voláteis utilizando Software CAD na investigação de passivo ambiental em um posto revendedor de combustíveis em Natal/RN. Dissertação de mestrado. Universidade Federal do Rio Grande do Norte, Departamento de Ciências e Engenharia de Petróleo, 2011.

FAVERA, C.H.D. Sites contaminados por hidrocarbonetos: principais técnicas de remediação e exemplo de aplicação. Trabalho de conclusão curso de Engenharia Civil. Universidade Federal de Santa Maria, 2008.

FERNANDES, H.G.; CHIAVONE-FILHO, O. Avaliação técnica da remediação de solo utilizando persulfato de sódio/ peróxido de hidrogênio. RnuPetro, 2, 2014, 31-38.

MARIANO, A. P. Avaliação do potencial de biorremediação de solos e de águas subterrâneas contaminados com óleo diesel. Tese de doutorado elaborada junto ao Programa de PósGraduação em Geociências e Meio Ambiente. 147p. 2006.

MARIANO, J. B. Impactos ambientais do refino de petróleo. Tese de doutorado. COPPE/UFRJ. 2001.

PALMROTH, M. R. T.; LANGWALDT, J.H.; AUNOLA, T.A.; GOI, A.; MÜNSTER, U. PUHAKKA, J.A.; TUHKANEN, T.A. Effect of modified Fenton's reaction on microbial activity and removal of PAHs in creosote oil contaminated soil. Biodegradation, 17 (2), 2006, 29-39. 